\title{
Prevention of and control measures for
}

\section{nosocomial coronavirus disease (COVID-19): 2020 recommendations by authors at Renmin Hospital of Wuhan University}

Lan $\mathrm{Li}^{1 \oplus}$, Siyang $\mathrm{Liu}^{1 \oplus}$, Yuhong $\mathrm{He}^{2 \oplus}$, Jinsong Wang ${ }^{2 \oplus}$, Wenmao Ding ${ }^{3, * \odot}$

\begin{abstract}
The rapid global spread of severe acute respiratory syndrome coronavirus 2 (SARS-CoV-2) has caused the coronavirus disease 2019 (COVID-19) pandemic. Although COVID-19 is a class B infectious disease, the prevention and control measures used for it in China are commonly used for class A infectious diseases. In the process of the spread of the disease, hospitals will be a key point to influence this pandemic. To prevent and control nosocomial infection of SARS-CoV-2, methods and measures were formulated from the relevant laws and regulations of the National Health Commission of the People's Republic of China, practical experience of the pandemic, and evidence-based medicine in the hospitals fighting this disease. Thus, this report may provide useful recommendations for the prevention and control of COVID-19 in hospitals and clinics.
\end{abstract}

Keywords: COVID-19; cross infection; prevention and control; public health surveillance; severe acute respiratory syndrome coronavirus 2

Since at least December 2019, some pneumonia cases of unknown origin were found in Wuhan, Hubei Province of China. The main manifestations of infected patients were fever, fatigue, and dry cough. Severely affected patients can rapidly develop acute respiratory distress syndrome, septic shock, uncorrectable metabolic acidosis, coagulation dysfunction, and even death [1]. A novel coronavirus has been identified as the pathogen, and then named 2019-nCoV on January 12, 2020 by the World Health Organization (WHO) and subsequently renamed as severe acute respiratory syndrome coronavirus 2 (SARS-CoV-2). Pneumonia caused by the novel coronavirus has been called novel coronavirus pneumonia (coronavirus disease 2019, COVID-19) [2, 3]. After hard work, the epidemic of COVID-19 in China has been controlled. Nevertheless, SARS-CoV-2 has spread quickly overseas where COVID-19 has become pandemic. The number of confirmed cases worldwide is still rising rapidly to date, and there is a possibility of resurgence in China. COVID-19 has been included in the class B category of infectious diseases, but the prevention and control

*Correspondence to: Wenmao Ding, Medical Administration Department, Renmin Hospital of Wuhan University, 238 JieFang Road, Wuchang, Wuhan 430060, China, e-mail: rm000104@whu.edu.cn

'Surgical Clinic, Renmin Hospital of Wuhan University, Wuhan 430060, China

${ }^{2}$ Infection Control Office, Renmin Hospital of Wuhan University, Wuhan 430060, China

${ }^{3}$ Medical Administration Department, Renmin Hospital of Wuhan University, Wuhan 430060, China

¿ Open Access. ๑ 2020 Li et al., published by Sciendo. (c) BY-NC-ND This work is licensed under the Creative Commons Attribution NonCommercial-NoDerivatives 4.0 License. 
measures of class A infectious diseases have been used by the National Health Commission of the People's Republic of China [4]. Many regions in China have launched a firstlevel response to major public health emergencies [5]. The main transmission routes of the novel coronavirus are considered to be respiratory droplet and contact transmission, but there are also aerosol and digestive tract transmission routes. Medical institutions are places where patients gather. Therefore, nosocomial infection is an important link in the outbreak of the disease, and the prevention and control of nosocomial infection is a key and difficult point in the spread of COVID-19. Therefore, it is very important to take appropriate and effective measures in hospitals to prevent and control nosocomial infection, control the pandemic spread of COVID-19, and protect the medical staff. In this article, we report our experience and recommendations for measures to prevent and control the nosocomial spread of COVID-19. This article has been prepared with due consideration of the AGREE reporting checklist [6] and the RIGHT statement [7] for clinical practice guidelines and health systems guidance.

\section{Scientific understanding of COVID-19 and related knowledge training is the basis of scientific development for prevention and control measures for hospital- acquired infection}

\section{Scientific recognition, and prevention and control knowledge training of COVID-19 are the premise of prevention and control of nosocomial infection}

SARS-CoV-2 infection training programs should be identified according to the responsibilities of the trainees, especially for high-risk departments, such as fever clinics, outpatient departments, pediatric outpatient departments, emergency departments, intensive care units (ICUs), and respiratory wards. The medical staff should master the knowledge, methods, and skills to avoid SARS-CoV-2 infection, so as to allow early detection, early reporting, early isolation, early diagnosis, early treatment, and early control [8]. In addition, SARS-CoV-2 infection training in hospitals can be achieved by combining professional training of medical staff with awareness and knowledge of hospital-acquired infection among nonmedical staff, so that epidemic prevention and control is everyone's responsibility.

\section{Establishment of correct control measures and regulations is a fundamental way to prevent and control hospital-acquired infection}

Establishing and improving the organizational management system for hospital-acquired infection by SARS-CoV-2

Medical and health institutions at all levels should quickly establish a hospital COVID-19 emergency command system to ensure the smooth development of hospital infection management from this framework [9]. The organization should be composed of the president of the hospital, the directors of the medical departments, the nursing department, the hospital infection management office, and the directors and head nurses of the relevant departments (e.g., respiratory and infectious departments). This organization should be responsible for the prevention and control of SARS-CoV-2 infection, the training to provide knowledge of hospital-acquired infection, the formulation of measures and systems for the prevention and control of hospital infection, the formulation of emergency plans for major hospital infection events, and the supervision of various rules and regulations.

To implement and coordinate the process, all departments of the hospital should make clear who is in charge of prevention and control of hospital infection, the contact person, and their corresponding responsibilities. Once there is a suspected or actual outbreak of SARS-CoV-2 infection, it must be reported promptly according to the regulations, and according to the relevant standards and processes, the emergency plan started, and there must be cooperation with the investigation and disposal of waste and contaminated material. Each department should establish a hospital infection management team under the responsibility of the department director and the head nurse, determine one monitor who will report the infection prevention and control situation daily, and establish a 3-level prevention and control system for the hospital, the department, and the monitoring personnel. For the departments at high risk for SARS-CoV-2-acquired hospital infection, a full-time hospital infection supervision group should be established to achieve effective supervision and management.

\section{The novel coronavirus hospital infection control system should be strictly implemented}

To standardize and guide the prevention and control of nosocomial infection with SARS-CoV-2 and stop the outbreak of nosocomial infection, a relatively independent fever clinic (emergency) and isolation observation room should be set up in the place easy to isolate, a special laboratory and radiation examination room should be attached, and an isolation toilet 
should be placed within a short distance. Eye-catching signs should be set up to facilitate the treatment of fever patients. An emergency isolation room should be set up in the general ward for the isolation and treatment of patients with suspected or confirmed infection. A special ward should be set up in the hospital for SARS-CoV-2 infection.

According to their clinical manifestations and epidemiological contact history, patients need to be isolated and separated into close contacts, suspected patients, and confirmed patients. For the different populations, stratified isolation is conducted in places with conditions corresponding according to the actual situation. Close contacts should take home-based isolation or centralized isolation under medical observation. Patients with suspected and confirmed infection must be isolated at separate medical points. The building layout and workflow of the ward used to isolate patients with suspected and confirmed infection should meet the relevant requirements of the technical code for hospital isolation.

According to the principle of isolation, patients with suspected infection should be isolated individually in single rooms, and patients with confirmed etiology can be placed in the same room for isolation. To strengthen the management of such patients, patients should wear masks and should not leave the ward. The ward should be set up with a warning area, and specially assigned personnel to check access. Without any accompanying person, the visitation system should be strictly controlled. Patients with severe SARS-CoV-2 infection should be treated in a special ICU ward or special ward with monitoring and rescue conditions.

The medical waste generated by the patients is included in the management of infectious medical waste, which is treated in strict accordance with the regulations on the management of medical waste and the measures for the management of medical waste in medical and health institutions. The medical waste should be put into a double-layered yellow medical waste bag that is then weighed and labeled with "special infection" and transferred out of the department.

\section{Effective disinfection measures taken by hospitals are important means to prevent and control the prevalence of COVID-19}

\section{Disinfection area}

The disinfection area should cover the places where there is direct or possible contact with the patients, pollutants from the patients, contaminated items, and the environment [10]. The areas should include the fever clinic (emergency), isolation observation room, pre-examination and triage office, a special ward for COVID-19 patients, isolation toilet, attached laboratory, radiation or computed tomography (CT) room, elevator for transferring patients, and medical staff office. Hospitals without a special COVID-19 laboratory and radiation $\mathrm{CT}$ room should strengthen disinfection management. These two places should be taken as the key monitoring objects for hospital infection.

\section{Disinfection methods}

The correct selection of disinfectants is one of the important factors to ensure the quality of disinfection. SARS-CoV-2 is sensitive to ultraviolet light and heat. Temperatures of $56^{\circ} \mathrm{C}$ for $30 \mathrm{~min}, 75 \%$ ethanol, ethyl ether, chlorine disinfectant, peracetic acid, and chloroform can effectively inactivate the virus. Chlorhexidine cannot effectively inactivate the virus. The concentration, dosage, and operation time of disinfection drugs must be strictly followed to ensure the best disinfection effect [11].

\section{Air disinfection}

Air disinfection should be conducted in accordance with the requirements of the management code of hospital air purification. People can open windows and ventilate the room 2 times a day for $30 \mathrm{~min}$ each time, or use an air disinfector to disinfect it 4 times a day for $2 \mathrm{~h}$ each time. A vacant room should be exposed to ultraviolet light once a day, more than $1 \mathrm{~h}$ each time. Personnel intensive areas, such as corridors, halls, lift, and so on, can be sprayed and sterilized with $500 \mathrm{mg} / \mathrm{L}$ chlorine dioxide using an ultra-low-volume sprayer. Terminal air disinfection should use an ultraviolet lamp to irradiate for at least $1 \mathrm{~h}$, and then ventilate; records should be made. It is advisable to use $3 \%$ peroxide or $5,000 \mathrm{mg} / \mathrm{L}$ peracetic acid or $500 \mathrm{mg} / \mathrm{L}$ chlorine dioxide using an ultra-low-volume sprayer to disinfect with $20-30 \mathrm{~mL} /$ $\mathrm{m}^{3}$ for $2 \mathrm{~h}$, close doors, and windows when disinfecting, and ventilate fully for at least $1 \mathrm{~h}$ before use. If the air conditioning system is set independently for an isolated ward, it can be used. Otherwise, it should be turned off. Special attention should be paid when using environmental disinfectants; the dilution ratio, contact time, and warning specified by the manufacturer should be observed carefully [12].

\section{The disinfection of ground and object surface should be carried out in strict accordance with the technical specifications for disinfection of medical institutions}

The surfaces of objects and floors in the room should be thoroughly wiped and disinfected with $1,000 \mathrm{mg} / \mathrm{L}$ 
chlorine-containing disinfectant or $500 \mathrm{mg} / \mathrm{L}$ chlorine dioxide, and records should be made [13]. In case of pollution with the patient's excreta, secretions, or vomitus on the surface and ground of environmental objects, a small amount of pollutants can be removed carefully by dipping 5,000-10,000 mg/L chlorine-containing disinfectant (or disinfectant wipes that can reach a high level of disinfection) with disposable absorbent materials (e.g., gauze or rags). A large amount of pollutants should be completely covered with disinfectant or bleaching powder containing water-absorbing ingredients, or fully covered with disposable water-absorbing materials, and then poured on the water-absorbing materials with a sufficient amount of 5,000-10,000 mg/L chlorine-containing disinfectant solution for $>30 \mathrm{~min}$ (or disinfectant wipes that can reach a high level of disinfection), and carefully removed. Contact with pollutants during the removal process should be avoided, and cleaned pollutants should be disposed of as medical waste.

As far as possible, disposable medical equipment, appliances, and articles should be preferentially selected for use. Commonly used items such as stethoscopes, infusion pumps, and sphygmomanometers should be thoroughly wiped and disinfected with $1,000 \mathrm{mg} / \mathrm{L}$ chlorine-containing disinfectant after each use. A thermometer can be soaked with $1,000 \mathrm{mg} / \mathrm{L}$ chlorine-containing disinfectant for $30 \mathrm{~min}$ after each use, and it is ready for use after cleaning and drying.

Disposable products should be used as far as possible for the ventilator pipes. If they are reused, they should be immediately soaked with $2,000 \mathrm{mg} / \mathrm{L}$ effective chlorine disinfectant, sealed, packed with double-layered white plastic bags, marked, and transported to the disinfection supply center immediately, and records should be made.

\section{Disinfection of other articles}

The bedsheet, quilt cover, and other fabrics used by a patient who has died should be disposed of as infectious medical waste (double-layered yellow medical waste bag); a quilt or clothing polluted by a patient's stool should be disposed of as infectious medical waste (double-layered yellow medical waste bag). Fabrics that need to be reused can be sealed in orange-red dissolvable packaging bags, marked with "COVID-19," immediately transported to a washing center, and a handover record made, or they need to be first soaked in $500 \mathrm{mg} / \mathrm{L}$ chlorine disinfectant for $30 \mathrm{~min}$, then cleaned, and disinfected as usual.

The domestic waste in the observation ward, fever clinic, and isolation ward should be treated as infectious waste. The infectious waste should be transported in a double-layered yellow medical waste bag with "COVID-19" marked on the bag. At the time of handover, $1,000 \mathrm{mg} / \mathrm{L}$ of chlorinecontaining disinfectant should be sprayed outside the yellow medical waste bag and then transported to a temporary storage room for medical waste. Choose 1-2 capable hazardous waste incineration disposal units, domestic waste incineration power generation enterprises, or cement kiln collaborative hazardous waste disposal enterprises as alternative emergency disposal units. The generated medical waste should be cleaned daily and the disposal time should not exceed $48 \mathrm{~h}$.

\section{Cadaver disposal and terminal disinfection}

The corpse should be handled promptly after the death of a patient with suspected or confirmed infection. Of note, $3,000-5,000 \mathrm{mg} / \mathrm{L}$ chlorine-containing disinfectant or $0.5 \%$ peracetic acid cotton ball or gauze should be used to fill all open channels of the patient including the mouth, nose, ears, and anus. Double-layered cloth to wrap the corpse should be used, and then a sealed anti-leakage double-layered corpse bag should be used to wrap it. A special vehicle should be directly sent to a designated place for cremation.

Personal belongings used by patients during hospitalization can be taken home with the patients or their families after disinfection treatment. After discharge, transfer, or death of patients with suspected or confirmed infections, the observation room and ward should be disinfected and relevant records should be made.

\section{Strengthening the self-protection of medical staff is an important part of the prevention and control of COVID-19 hospital infection}

The scientific and effective protection of medical personnel is of great importance in overcoming the COVID-19 pandemic [14]. When entering into or leaving the outpatient and emergency department, fever outpatient department, observation room, or the isolation ward, medical staff should correctly wear and take off the protective equipment.

According to the risk of infection, medical staff should take corresponding grade protection. The first-level protection applies to the general diagnosis and treatment activities of the general outpatient and general ward. The staff should wear a disposable work cap and disposable medical surgical mask and work clothes, and wear disposable latex gloves when necessary. Staff performing general diagnosis and treatment activities in 
the fever clinic should wear work clothes, disposable work caps, medical protective masks, disposable impermeable isolation clothing or protective clothing, latex gloves, and protective glasses. The second level of protection is suitable for medical staff when they are engaged in the diagnosis and treatment activities that involve close contact with patients (such as the observation room and isolation ward). The staff should wear work clothes, disposable work caps, medical protective masks, protective glasses or protective screens, disposable impermeable isolation clothing or protective clothing, and disposable latex gloves and should wear disposable shoe covers if necessary. The third-level protection is to wear a full-scale protective mask, a full-scale respiratory protective device, or a positive pressure head cover based on the second-level protection when conducting work with the patient involving sputum aspiration, respiratory sampling, tracheal intubation, and tracheotomy, which may cause the spray or splashing of the patient's respiratory secretions.

In the process of protection, it should be noted that disposable protective articles should be used once, and cross infection easily occurs in the process of reuse of contaminated protective articles. When sampling, double-layered latex gloves can generally be worn. The tightness of wearing medical surgical masks or medical protective masks should be checked to ensure the isolation effect, and the efficiency time of using the medical protective masks is $4-6 \mathrm{~h}$.

\section{Summary}

Hospitals at all levels are not only a key place to prevent and treat COVID-19, but also high-risk areas for cross infection. In hospitals, prevention and control is the key to reduce nosocomial infection, ensure the safety of doctors and patients, and prevent the spread of SARS-CoV-2.

Authors contributions. All authors contributed to the conception and design of the study and drafting the initial manuscript. LL, SL, and JW contributed to the acquisition of data, and LL, YH, and WD contributed to its analysis and interpretation. LL and WD critically revised the manuscript. All authors approved the final version submitted for publication and take responsibility for statements made in the published article.

Acknowledgment. The authors did not receive any specific grant for this work from any funding agencies in the public, commercial, or not-for-profit sectors.

Conflicts of interest statement. The authors have each completed an International Committee of Medical Journal
Editors Uniform Disclosure Form for Potential Conflicts of Interest. None of the authors has declared any potential conflict of interest with respect to the research, authorship, and/or publication of this article.

Data sharing statement. No new data sets were generated or analyzed during the present study. The present guidelines are based on the references cited and the clinical experience of the authors.

\section{References}

[1] General Office of the National Health Commission, Office of the National Administration of Traditional Chinese medicine. Notice on the issuance of a new programme of diagnosis and treatment for coronavirus pneumonia plan (trial version 7). National Health Office Medical Letter (2020) No. 184 [Internet]. Beijing: National Health Commission of the People's Republic of China; 2020 March 3 [cited 2020 Jul 20]. Available from: http://www.nhc.gov.cn/yzygj/ s7653p/202003/46c9294a7dfe4cef80dc7f5912eb1989.shtml

[2] World Health Organization. Surveillance case definitions for human infection with novel coronavirus ( $\mathrm{nCoV}$ ) Interim guidance (version 1) [Internet]. Geneva: World Health Organization; 2020 January 15 [cited $2020 \mathrm{Feb} 8$ ]. Available from: https://apps.who.int/ iris/bitstream/handle/10665/330376/WHO-2019-nCoV-Surveillancev2020.1-eng.pdf

[3] National Health Commission. Notice of the revision of the English naming of the new coronavirus pneumonia. National Health Medical Letter (2020) No. 70 [Internet]. Beijing; The National Health Commission of the People's Republic of China; 2020 February 22 [cited 2020 Mar 20]. Available from: http:// www.nhc.gov.cn/yzygj/s7653p/202002/33393aa53d984ccdb1053a 52b6bef810.shtml

[4] Department of Disease Control and Prevention. Announcement of The National Health Commission of the People's Republic of China [Internet]. Beijing; 2020 January 20 [cited 2020 Mar 20]. Available from: $h t t p: / / w w w . n h c . g o v . c n / j k j / s 7916 / 202001 / 44 a 3 b 8245 e 8049 d 283$ $7 a 4 f 27529 \mathrm{~cd} 386 . \mathrm{shtml}$

[5] CCTV News Client. Pneumonia outbreak 24 hours the Party Central Committee set up a leading group to deal with the epidemic 30 provinces and autonomous regions have started a first-level public health incident response. [Internet] Beijing: Central Radio and Television Station CCTV Network; 2020 January 25 [cited 2020 Jul 20]. Available from: $h t t p: / / m . n e w s . c c t v . c o m / 2020 / 01 / 25 /$ ARTIVdXxhUzobSvozuL6cQ44200125.shtml

[6] Brouwers MC, Kerkvliet K, Spithoff K, et al; AGREE Next Steps Consortium. The AGREE reporting checklist: a tool to improve reporting of clinical practice guidelines. BMJ. 2016; 352:i1152. doi: 10.1136/bmj.i1152

[7] Chen Y, Yang K, Marušic A, Qaseem A, Meerpohl JJ, Flottorp S, et al.; RIGHT (Reporting Items for Practice Guidelines in Healthcare) Working Group. Reporting Tool for Practice Guidelines in Health Care: The RIGHT Statement. Ann Intern Med. 2017; 166:128-32.

[8] General Office of the National Health Commission. Technical guidelines for novel coronavirus infection prevention and control in medical institutions (first edition). National Health Office 
Medical Letter (2020) No. 65. [Internet]. Beijing: Office of the National Health and Health Commission; 2020 January 22 [cited 2020 Jul 20]. Available from: http://www.gov.cn/zhengce/ zhengceku/2020-01/23/content_5471857.htm

[9] Li SY, Huang WZ, Liao XL, Li DD, Du LY, Song JJ, et al. Disease control of 2019 novel coronavirus infection in hospital: West China urgent recommendation. Chinese J Evid Based Med. 2020; 20:125-33. [in Chinese, English abstract]

[10] Lin J-Y, Zou Q, Zhang X-C, Zhou D-H, Lin W-S, Yin W-W, et al. Survey and analysis of disinfection condition in 13 SARS hospitals of Guangdong Province. Chinese J Disinfect. 2005; 22:271-74. [in Chinese, English abstract]

[11] General Office of the National Health Commission. Notice by the Office of the National Health Commission on the issuance of a new programme for the prevention and control of coronavirus pneumonia (fifth edition). National Health Office CDC Letter (2020) No. 156 [Internet]. Beijing: National Health Commission of the People's Republic of China; 2020 February 21 [cited 2020 Jul 20]
Available from: http://www.nhc.gov.cn/jkj/s3577/202002/a5d6f7b8c4 8c451c87dba14889b30147.shtml

[12] Kim JY, Song JY, Yoon YK, Choi S-H, Song YG, Kim S-R, et al. Middle East Respiratory Syndrome infection control and prevention guideline for healthcare facilities. Infect Chemother. 2015; 47:278-302.

[13] National Health Commission of the People's Republic of China, editor. Liang X, Feng, Z, Li L, translators in chief for the Chinese Preventive Medicine Association. Guidance for corona virus disease 2019: prevention, control, diagnosis and management [Internet]. Beijing: People's Medical Publishing House; 2020. [cited 2020 July 27]. Available from: https://www.yoifos.com/sites/default/files/ covid_19_guideline_chn.pdf

[14] Office of the National Health Commission. Notice on the issuance of a new programme of diagnosis and treatment of pneumonia for coronavirus infection (trial version 4). National Health Office Medical Letter (2020) No. 77 [Internet]. Beijing: National Health Commission; 2020 January 27 [cited 2020 Jul 20]. Available from: http://www.gov. cn/zhengce/zhengceku/2020-01/28/content_5472673.htm 